\title{
O ensino da Língua Estrangeira como ferramenta para a emancipação das pessoas da Educação de Jovens e Adultos: potencialidades e reflexões
}

\author{
José Veiga Vinal Junior $^{1}$ \\ Universidade do Estado da Bahia \\ veigavinal@hotmail.com
}

\section{Resumo}

Neste artigo buscamos, traçar algumas reflexões relativas ao uso da língua estrangeira como ferramenta para a emancipação das pessoas da Educação de Jovens e Adultos (EJA). Nesse processo, abordamos o conceito de emancipação e correlacionamos as possíveis ligações entre ensino e aprendizagem de língua estrangeira e suas potencialidades como instrumento social para os sujeitos da EJA. Também apontamos problemáticas e desafios que impossibilitam ou que dificultam a percepção do ensino da língua estrangeira como instrumento auxiliar no processo emancipatório das pessoas da EJA. Tratamos ainda de questões metodológicas e da importância da formação do professor de língua estrangeira.

Palavras-chave: emancipação, ensino de língua estrangeira, educação de jovens e adultos

\begin{abstract}
This article aims to reflect upon the use of a foreign language as a tool for helping people from the Youth and Adult Education (EJA) programs in Brazil in their process of emancipation. In doing so, we discuss the concept of emancipation and the possible relation between the process of teaching and learning foreign languages and its possibilities as a social instrument for people involved in the youth and adult education. In addition to that, we highlight some issues and challenges that interfere in the emancipation process of Youth and Adult Education students through the teaching of
\end{abstract}

\footnotetext{
${ }^{1}$ Professor da Universidade Estadual da Bahia. Departamento de Ciências Humanas - Campus I. Mestre em Educação de Jovens e Adultos pela UNEB. Doutor em Língua e Linguística pela Universidad de Vigo (Espanha).
} 
O ensino da LE como ferramenta para a emancipação...

foreign languages. We also discuss methodological issues and the importance of foreign language teacher training.

Keywords: emancipation, foreign languages teaching, youth and adult education

\section{Introdução}

Os ninguéns

Os ninguéns: os filhos de ninguém, os donos de nada.

Que não são, embora sejam.

Que não falam idiomas, falam dialetos.

Que não fazem arte, fazem artesanato.

Que não são seres humanos, são recursos humanos.

Que não aparece na história universal, aparecem nas páginas policiais da imprensa local.

Os ninguéns, que custam menos do que a bala que os mata.

(O livro dos abraços. Galeano, 2002, p. 71)

Partimos das palavras de Galeano (2002), conforme a epígrafe acima, para pensar em algumas questões que serão abordadas neste artigo. A sensação de 'estar fora de' fica evidente nas palavras do autor. Essa impressão nos leva a refletir sobre uma ação necessária para colocar esse indivíduo numa posição de 'estar dentro de', 'ser autônomo', 'estar emancipado', 'ser emancipado'.

O Dicionário Aurélio da Língua Portuguesa (data, página) define a palavra emancipação como "o ato ou efeito de emancipar, libertação ou o estado daquele que, livre de toda e qualquer tutela, pode administrar-se livremente".

Buscamos, assim, trazer uma reflexão sobre como o ensino de línguas estrangeiras pode servir como uma ferramenta numa perspectiva para a emancipação das pessoas da EJA. Desse modo, o primeiro passo, então, é traçar uma definição desta emancipação que tratamos neste artigo. Almejamos, nesse sentido, nos ater à acepção de emancipação não somente como está exposto pelo dicionário da língua portuguesa, mas também por autores como Paulo Freire (1992, 1981, 1997) e Boaventura Santos (2002, 2008). Apesar de não coadunarem de maneira integral suas visões sobre emancipação, ambos os citados autores, ao tratarem sobre esse assunto, entendem que ato de se 
emancipar possui ligação direta com o ato de libertar-se: em outras palavras, com o ato de tornar-se um sujeito autônomo. Assim, tomamos como reflexão as palavras de Pereira, que indaga o seguinte:

[...] ¿qué es una humanidad emancipada? Por supuesto que existen diferentes posibles respuestas, pero puede pensarse que un consenso importante podría construirse en torno a la idea de autonomía, por lo tanto, podría decirse que una humanidad emancipada sería una humanidad en la que las personas fuesen seres autónomos. La definición de autonomía en la que nos basaremos proviene de Kant, quien sostiene que todo ser racional, gracias a esta condición, posee una voluntad autónoma, es decir, es capaz de autolegislar en concordancia con la ley moral. Este carácter autolegislativo de la voluntad racional es lo que la distingue como voluntad libre, debido a que es capaz de someterse a sus propias leyes. (2007, p.231)

Nesse contexto, emancipar-se está além da ideia que muitos têm, relacionada quase que exclusivamente ao acesso ao trabalho e aos bens de consumo. Na perspectiva freiriana, emancipar-se toma efeito de direito à vida, ao direito e à liberdade.

Defendemos, então, que emancipar-se, nessa conjuntura, é o ato de andar por si só; de escrever sua história; de produzir modificações em sua vida e na vida de sua sociedade. Ou seja, é ter voz e vez. Ser um sujeito que influencia a sua comunidade e a sociedade em geral. Não obstante, devemos conceber que vivemos numa cidade globalizada, competitiva e altamente consumista. Assim, os indivíduos da EJA estão sujeitos a essa estrutura e comportamento social. Por isso, para entender o que é emancipar-se é preciso estar também alertados para essas questões. Queremos, porém, deixar claro que essa não é nossa vertente principal quando defendemos, neste escrito, o ato da emancipação.

Discorrer em relação às práticas educativas emancipatórias nos leva ao processo de compreensão sobre que emancipação é esta que estamos tratando. Isso é de fato importante, uma vez que o conceito dessa palavra no contexto sociocultural e econômico atual tende a possuir uma definição relativamente ampla - por vezes complexa e até paradoxal. Contudo, não é nosso interesse discorrer neste momento 
sobre a exegese deste assunto. Mas, por ele possuir certa complexidade e, também, para que tenhamos uma linha de entendimento a seguir sobre essa terminologia que debatemos neste artigo, apoiamo-nos nas considerações defendidas por Lopes (2010), para quem a emancipação é:

[...] um conceito complexo que foi abraçado como um norteador da modernidade, principalmente a partir da proposta iluminista (Sec. XVIII) de trazer mais clareza à verdade do mundo e erradicar as "visões erradas" que as pessoas nutriam sobre a natureza e a vida. Emancipar a sociedade significaria libertar os sujeitos dos preconceitos a fim de que pudessem "enxergar melhor" a "realidade". Porém, a emancipação, no momento em que se tornou um conceito absorvido por variados contextos sócio-políticos, ganhou orientações diferenciadas que vivificaram outros sentidos para além dos iluministas. (p. 127)

Lopes (2010), ao questionar a emancipação, expressa que esta categoria se insere em duas vertentes principais não excludentes, mas, concomitantemente, conflituosas, já que conseguem conviver no mesmo espaço social ou processo grupal. A primeira vertente propende a trazer a ideia de uma dimensão transcendente, "na qual se emancipar faz referência a seguir o caminho de uma verdade maior para o engrandecimento da nação, para a felicidade, para a evolução espiritual, para a maturidade ou a plenitude moral" (Ibidem, p.132).

Nessa conjuntura iluminista, a finalidade da educação baseiase no anseio de libertar o ser humano de todos os vínculos incoerentes e das ilusões sem fundamento, conduzindo-o às verdades do mundo. $\mathrm{Na}$ segunda perspectiva, a emancipação delineia-se a partir de dinâmicas definidamente localizadas, nas quais "os processos emancipatórios valem mais pelos movimentos que mobilizam no corpo social do que propriamente pelo fomento de verdades triunfantes" (Ibidem, p. 132).

Para Lopes (2010), a dualidade dos distintos aspectos que envolvem a conceituação de emancipação pode ser encontrada também no pensamento de Boaventura Santos (2002) ao indagar o conceito de emancipação social. 
É possível ou legítimo defini-la abstratamente? Se é verdade que não há uma, mas várias globalizações, não será igualmente verdade que não há uma, mas várias formas de emancipação social? Tal como a ciência, não será a emancipação social de natureza multicultural, definível e validável apenas em certos contextos, lugares e circunstâncias, uma vez que o que é emancipação social para um grupo social ou em um dado momento histórico pode ser considerado regulação ou mesmo opressão social para outro grupo social ou em um momento histórico seguinte ou anterior? Todas as lutas contra a opressão quaisquer que sejam seus meios e objetivos são lutas pela emancipação social? É possível emancipação social sem emancipação individual? Emancipação social para quem e para quê, contra quem e contra quê? Quem são os agentes da emancipação social? Há algum agente privilegiado? (SANTOS, 2002, p. 23- 24).

As indagações de Santos (2002) em relação à conceituação de emancipação social e às questões que motivaram e motivam diversas ações que se definem como emancipatórias nos levam à necessidade de entender a emancipação social como sendo mais que a concepção do fomento de um processo libertário que levaria à emancipação da sociedade a um local de sonhada redenção: seja ao referido como paraíso cristão, à sociedade comunista ou ao mundo mais feliz. Dessa maneira, ao pensar nas definições de emancipação, é preciso levar em conta o contexto atual na qual o mundo insere-se.

Ocorreram relevantes mudanças no aspecto econômico, social e político. Além disso, as sociedades trazem consigo um contexto no qual se observam crises de paradigmas e de questionamentos das metanarrativas a partir do desenvolvimento do pensamento pósmoderno. Nesse sentido, a discussão sobre emancipação ganha um status instigante e desafiador. Ou, como defende Carvalho (2008), "ousar pensar a emancipação nos tempos de mudanças amplas e radicais, de insegurança e de instabilidades, de emergência da pluralidade do novo [...] é colocar-se no olho do furacão" (p. 3).

Nesse âmbito, há de se pensar a emancipação, antes de tudo, como um processo e não dentro de uma perspectiva teleológica conduzida por um agente social como garantia do advir de uma 
O ensino da LE como ferramenta para a emancipação...

realidade futura:

A emancipação não é mais do que um conjunto de lutas processuais, sem fim definido. O que a distingue de outros conjuntos de lutas é o sentido político das processualidades das lutas. Esse sentido é, para o campo social da emancipação, a ampliação e o aprofundamento das lutas democráticas em todos os espaços estruturais da prática social (Santos, 2008, p. 277).

Por outro lado, o conceito de emancipação na perspectiva freiriana nos leva a um entendimento baseado na consideração da dimensão humana. Esta, por sua vez, associa-se de maneira intrínseca com a educação libertadora e humanizadora, cuja base tem seu princípio na educação popular como paradigma latino-americano. Nessa conjuntura, faz-se necessário entender que 'popular' toma como referência a categoria 'oprimido', e é nela que o processo de entender emancipação na perspectiva de Freire perpassa pelo entendimento da total ligação com a busca do seu viés contraditório: a opressão (FEITOZA, 2008).

Esse estado de opressão agrega o recorte de classe social, já que se poderia entender que estes grupos seriam os que possuem necessidade da acepção de liberdade, autonomia e emancipação, passíveis de conquista pela práxis revolucionária desses sujeitos. No paradigma freireano, a luta pela emancipação traz, em seu cerne, aspectos como: a esperança nos humanos, a busca pela superação do paradoxo oprimido/opressor e a formação de 'homens novos', em relações de liberdade, igualdade e emancipação. Para Feitoza: "Freire acentua a necessidade de uma educação humanizante, circunscrita às sociedades e homens concretos, superadora da alienação e potencializadora da mudança e da libertação social" (2008, p.43).

Desse modo, a emancipação na perspectiva freireana aparece como um grande atingimento político a ser realizado pela práxis humana, num processo de luta incessante em busca da libertação das pessoas cujas vidas encontram-se em processo de desumanização pelo efeito da opressão. Por tanto, a emancipação não deve ser encarada como um projeto a ser desenvolvido num futuro distante, mas, contrariamente, esta deve compor-se como um processo em 
construção, um vir a ser. Fundamenta-se, segundo o próprio Paulo Freire, em um fazer cotidiano e histórico envolvido por desafios e possibilidades que precisa ser vivido e sentido nos vários espaços sociais, efetivando-se ao mesmo tempo no cotidiano e na história.

Partindo dessa perspectiva, a dinâmica do processo de emancipação "tanto se verifica em casa, nas relações pais, mães, filhos, filhas, quanto na escola [...] ou nas relações de trabalho. O fundamental, se sou coerente progressista, é testemunhar [...] o meu respeito à dignidade do outro ou da outra" (FREIRE, 2000, p.37).

Esse processo demanda compromisso e engajamento político com a mudança das condições existenciais de vida dos oprimidos, tendo como base uma permanente indagação crítica, fundada no diálogo e na linguagem das possibilidades.

Sem embargo, na visão de Freire (1992), atingir o entendimento mais crítico da condição de opressão não libertaria necessariamente os oprimidos. Porém, o processo de desvelamento seria "um passo para superá-la desde que se engajem na luta política pela transformação das condições concretas em que se dá a opressão" (p. 32).

Se tomarmos como exemplo as 'Primeiras palavras' dentro da obra Pedagogia da Esperança, podemos perceber que Paulo Freire (1992) deixa claro sua crença em relação à necessidade da esperança e do sonho como critérios fundantes para a existência humana e a inescusável luta para fazê-la melhor. Para ele, a esperança é uma necessidade ontológica, dado que sem um mínimo de esperança não há possibilidade de que consigamos sequer começar o embate. Contudo, alerta-nos a refletir que não se pode atribuir à esperança o poder de transformação da realidade, pois essa seria uma maneira de cair na desesperança, já que "enquanto necessidade ontológica a esperança precisa da prática para tornar-se concretude histórica” (Freire, 1992, p. 11). Além disso, Freire sinaliza para a necessidade de uma educação da esperança, entendida como de importância essencial no âmbito individual e no social, para que essa não seja vivida de maneira desacertada e acabe por deslizar para a desesperança e para o fatalismo (FREIRE, 1992).

Uma vez tendo apresentado nosso entendimento sobre emancipação, importa-nos, nos parágrafos seguintes, desenvolver 
O ensino da LE como ferramenta para a emancipação...

algumas ideias que nos levam a refletir sobre a relação entre ensino de línguas estrangeiras e a emancipação.

\section{Emancipação e ensino de língua estrangeira para a EJA}

Percebe-se que cada vez mais as sociedades e as economias mundiais tendem a manter entre si uma relação de interdependência. É imprescindível, dentro dessa conjuntura socioeconômica, possuir um conhecimento de línguas estrangeiras para que os diferentes indivíduos possam desenvolver e ampliar as condições necessárias e as possibilidades de acesso ao conhecimento científico e tecnológico produzido.

Se pensarmos nesses aspectos, podemos entender que, para exercer a cidadania, é preciso se comunicar: deve-se conseguir encontrar informações, assimilá-las, interpretá-las e, consequentemente, argumentar. Essas questões tomam uma dimensão ainda maior quando pensamos especificamente na EJA. Sendo indivíduos que se pressupõe estarem inseridos no mercado de trabalho e na vida social, o desenvolvimento dessas habilidades propiciadas pelo ensino da língua estrangeira (LE) é de fundamental importância para sua construção e formação.

Para Filho (2000), a educação de jovens adultos deveria valorizar as competências sociais dos adultos. O autor também entende que esse procedimento cobra do professor um diálogo aberto com o adulto, permitindo que assuntos de seu interesse imediato, de sua experiência de vida, de sua oralidade e de suas aspirações apareçam em sala de aula. Consequentemente, os textos em língua estrangeira trabalhados em sala de aula deveriam, de alguma maneira, possibilitar esse diálogo aberto com o adulto por meio de temáticas pertinentes a seu mundo. O que se vê muitas vezes nas aulas de LE para EJA, e tomemos como exemplo a classe trabalhadora, é o uso de técnicas totalmente desinteressantes no que concerne ao seu modo de vida, seu ambiente, sua história e sua construção identitária.

É fundamental perceber que as ações que implicam a maneira como esse alunado entende os textos - sejam eles lidos ou ouvidos ou na produção de novos textos - poderão gerar ações e práticas de sua participação em um contexto social e crítico mais amplo, imbricadas 
intimamente na e para a formação deles como cidadãos atuantes em sua sociedade, promovendo, assim, processos de emancipação.

Nesse contexto, de maneira muito parecida, quando se trabalha com temas transversais nas práticas de sala de aula, pode-se dar a esse alunado a possibilidade de ter um espaço onde se perceberão as formas de agir no mundo e sua relação quanto à participação efetiva como cidadãos. Em outras palavras, esse ensino de línguas deve ser trabalhado de maneira natural e contextualizada com o mundo do público da EJA. Para Figueiredo (1997, apud Silva, 2010, p.42), “a aquisição de uma segunda língua requer uma comunicação natural, pois os falantes não estão preocupados com forma de suas sentenças, mas sim com as mensagens que estão exprimindo e entendendo".

Ao pensarmos nos sujeitos da EJA, principalmente a classe trabalhadora, questões que envolvem a forma, a maneira, a metodologia com a qual o professor constrói suas aulas incidem diretamente sobre a possibilidade do sucesso. É importante que o professor entenda que essa classe trabalhadora, muitas vezes, possui uma jornada de trabalho longa. Às vezes, uma aula desestimulante e longe de sua realidade pode colocar à prova a própria frequência e interesse deste aluno.

Isso nos faz lembrar da função equalizadora da EJA definida no Parecer CNE/CEB nº 11/2000, quando nos diz que:

A equidade é a forma pela qual se distribuem os bens sociais de modo a garantir uma redistribuição e alocação em vista de mais igualdade, consideradas as situações específicas. [...] Neste sentido, os desfavorecidos frente ao acesso e permanência na escola devem receber proporcionalmente maiores oportunidades que os outros. Por esta função, o indivíduo que teve sustada sua formação, qualquer que tenha sido a razão, busca restabelecer sua trajetória escolar de modo a readquirir a oportunidade de um ponto igualitário no jogo conflitual da sociedade. (BRASIL, 2000a, p. 40)

Desse modo, com base nas discussões promovidas na sala de aula, novas formas de entender o mundo poderão ser construídas. Ademais, de uma renovada compreensão de mundo, a compreensão do ensino de LE na EJA, sob essa ótica, possibilitará a percepção da 
escola como um espaço onde se poderá executar a construção de novas perspectivas de si mesmo. Sendo assim, o alunado da EJA terá a oportunidade de participar da construção do conhecimento em conjunto, utilizando-se de sua própria história como uma fonte de e para a aprendizagem. Partindo dessas premissas, o ensino e aprendizagem de línguas podem colaborar para uma educação permanente e ao longo da vida (Freire, 1993), (Brandão, 2002). Isso coaduna no exposto pela CNE/CEB $n^{\circ} 11 / 2000$ :

Esta tarefa de propiciar a todos a atualização de conhecimentos por toda a vida é a função permanente da EJA que pode se chamar de qualificadora. Mais do que uma função, ela é o próprio sentido da EJA. Ela tem como base o caráter incompleto do ser humano cujo potencial de desenvolvimento e de adequação pode se atualizar em quadros escolares ou não escolares. (BRASIL, 2000a, p.41)

É necessário que falemos dentro deste processo sobre a prática pedagógica do professor de LE na Educação de Jovens e Adultos. Percebe-se que, em muitas escolas, esses professores tendem a planificar e executar suas aulas como sendo majoritariamente expositivas, utilizando-se, muitas vezes, de material apostilado e de livros didáticos. Esses recursos têm como conteúdo de ensino: cumprimentos; dias da semana e meses, profissão; cores; verbo to be, verbo to have, gustar, ser y estar; pronomes pessoais; nacionalidades; artigos, números, adjetivos e preposições; formas interrogativas e respostas curtas.

Metodologias como leitura, interpretação e discussão a partir de entrevistas, programações de televisão, textos publicitários, cartas, e-mails, reportagens, documentários, classificados, linguagem publicitária e de textos literários, além dos usos de enciclopédias e de dicionários, de receitas, e de outros materiais tão integrantes do cotidiano do aluno da EJA são utilizados apenas em alguns momentos (ou nunca o são).

A preferência pelo ensino de formas gramaticais, funcionais ou lexicais descontextualizadas do mundo do público da EJA só implicará, quando conseguir implicar, a formação de um alunado que repete formulações apreendidas, mas não entende a relação destas com 
as necessidades de seu cotidiano. Melhor dizendo, não são capazes de executar uma voz crítica diante de sua sociedade uma vez que mais parecem 'meros repetidores' do que cidadãos preparados para uma sociedade contemporânea, competitiva e globalizada, na qual se exige um trabalhador que saiba envolver-se nas necessidades do mundo do trabalho e impor-se, mostrando sua voz e sua vez. Esse é um ponto importantíssimo quando pensamos nos jovens e adultos trabalhadores.

O professor e a escola, mesmo que de uma maneira não proposital, acabam discriminando um público que já enfrenta tantos outros processos que por fatores sociais, históricos ou culturais os colocam em posição de exclusão, tais como: a idade avançada, dificuldades no domínio da norma culta da língua, pertencimento a famílias numerosas, pobres e, em sua maioria, afrodescendentes. Em relação a essa questão específica, Gomes defende que: "Os negros e as negras são, na maioria das vezes, os principais sujeitos da EJA no Brasil. No entanto, essa forte presença negra não tem sido suficiente para garantir a realização de um trabalho pedagógico e de uma discussão séria e competente sobre a questão racial na educação de jovens e adultos" (2005, p.93).

É triste perceber quando o próprio professor de LE, por exemplo, pende-se a possuir um olhar 'preconceituoso' sobre seu alunado da EJA, interpretando que, por esse ser um público cujo alunado já tem uma idade maior, por serem trabalhadores, aposentados ou por adentrarem no ensino na idade regular, não teriam condições ou capacidade para enfrentar estruturas mais complexas e contextualizadas em sala de aula.

Em outras palavras, preferem então adotar uma postura de aula monológica, sem atentar para o encontro interacional e o mundo social que envolve esse alunado, tendo perceptível inclinação para ensinar itens lexicais e gramaticais descontextualizados, aplicando exercícios com textos ou tarefas que buscam avaliar seu alunado através somente da fixação-reprodução-repetição ou imitação. Dentro de todo esse processo, soma-se, também, a autoexclusão do alunado da EJA, que, muitas vezes, vê como desnecessário a aprendizagem de uma segunda língua, baseando essa ideia em sua idade 'avançada', o que é bem comum nas salas da EJA. Nesse contexto, Silva (2010) afirma que: 
O ensino da LE como ferramenta para a emancipação...

Outro fator preocupante para os alunos da EJA é que eles se sentem incapazes de aprender esta língua por terem idade avançada. Muitos reclamam que não tem mais paciência para aprender "isso" e que não conseguem pronunciar as palavras. É preciso motivar esses estudantes e levantar a autoestima deles, mostrando que são capazes sim, pois a idade não é fator tão relevante quando a pessoa se sente motivada a aprender determinado assunto. A idade pode determinar o modo pelo qual o indivíduo aprende uma segunda língua. Mas, as oportunidades para a aprendizagem, a motivação para aprender, e as diferenças individuais são também fatores determinantes para o sucesso na aprendizagem. (2010, p.44)

Ou seja, um ensino sem desafio, aprendizagem sem desafio e vida sem desafio (Freire, 1997). Dessa maneira, 'criam-se' alunos que aplicam regras gramaticais de maneira mecânica, contudo, sem ferramentas necessárias para desenvolver procedimentos ou estratégias de compreensão ou produção de textos. Além do mais, esses alunos não serão capazes de entender a relação e importância da aprendizagem da língua estrangeira para a formação de um cidadão pós-moderno, preparado para o mundo do trabalho, engajado crítica e politicamente, entendedor das mais variadas culturas.

A ênfase em aulas expositivas de LE nas turmas de EJA, quando essas acontecem, impossibilita esse alunado de enxergar o espaço da sala de aula como um universo onde ele também deva ser ouvido, visto e entendido; colocando assim uma visão de ensino e de aprendizagem que tem como centro a figura do professor. Um ensino de língua estrangeira que possibilite emancipação para o público da educação de jovens e adultos precisa necessariamente estar vinculada a uma abordagem sociointeracional da linguagem.

Acreditamos inclusive que o ensino de línguas possa ajudar no processo para diminuir o analfabetismo e o analfabetismo funcional, problemática que, segundo as últimas pesquisas do $\mathrm{IBGE}^{2}$, atinge um em cada cinco brasileiros atualmente. Para Oliveira (2009, 2005), o analfabetismo se constitui como um indicador cultural que nomeia

\footnotetext{
${ }^{2}$ Disponível em:http://seriesestatisticas.ibge.gov.br/series.aspx?t=taxaanalfabetismo\&vcodigo $=$ PD 384
} 
formas de diferenças de capacidades individuais e de classes sociais. Sendo uma ferramenta que contribui para o desenvolvimento linguístico e comunicacional, defendemos que o estudo de uma segunda língua pode somar-se a outras ferramentas da erradicação e diminuição do analfabetismo em suas mais variadas acepções.

Para que consigamos de fato contribuir para o processo de emancipação do público de jovens e adultos, é necessário que as aulas de língua estrangeira sejam planificadas sob o prisma de uma abordagem sociointeracional e intercultural da linguagem. Esse procedimento dará condições para que a LE seja um meio de interação entre os sujeitos de uma comunidade e seus mais variados contextos. Ou seja, essa abordagem de ensino primeiramente respeita o indivíduo e lhe dá condições de participar de uma visão dialógica, podendo, dessa maneira, situá-los histórico, social e culturalmente (ARROYO, 2005).

Na visão de Pereira (2007), as disciplinas das áreas humanas e as línguas estrangeiras se encaixam nesse universo - são deveras importantes para a formação de um indivíduo autônomo e emancipado.

Se observarmos isso de uma maneira mais global, tratando-se, em específico, da classe trabalhadora da EJA, todo esse processo ganha uma dimensão ainda mais importante, pois parte dessa clientela já é participante de contextos de trabalho e está inserida em interações sociais que podem ser consideradas mais definidas e complexas. Esse fato demanda a esses trabalhadores uma necessidade de desenvolver meios adequados de agir e interagir no mundo através do discurso. Nesse sentido, defendemos um ensino de línguas para a EJA para além do mercado de trabalho. Assim sendo, coadunamos com as palavras das OCEM (Orientações Curriculares para o Ensino Médio) quando afirmam que:

[...] a formação humana, no seu sentido lato, com acesso ao universo de saberes e conhecimentos científicos $e$ tecnológicos produzidos historicamente pela humanidade, integrada a uma formação profissional que permita compreender o mundo, compreender-se no mundo e nele atuar na busca de melhoria das próprias condições de vida e da construção de uma sociedade socialmente justa. A perspectiva precisa ser, portanto, de formação na vida $e$ 
O ensino da LE como ferramenta para a emancipação...

para a vida e não apenas de qualificação do mercado ou para ele. (BRASIL, 2006, p. 17)

Se tomarmos teorias como as do letramento - baseadas em estudos como os de Street (1984), Kleiman (1995), Soares (2002, 1999, 2004) - e as de educação linguística - como as de Bagno; Rangel (2005) e Brito $(1997,2007)$-, poderemos observar que o ensino e a aprendizagem de língua estrangeira sob essa perspectiva pode de fato gerar emancipação. Em especial, se partimos do pressuposto que esse processo dará acesso à língua e, consequentemente, às formas cultas da língua; e ter acesso à língua é ter acesso às oportunidades, é ter acesso ao poder (BARTHES, 1997; FOUCAULT, 1996, 2006, 1979).

Para que o ensino de línguas estrangeiras logre, de fato, todos esses frutos positivos na educação de jovens e adultos, em especial da classe trabalhadora, é preciso de fato ter consciência da importância do material utilizado. A educação de jovens e adultos é um segmento que necessita de material apropriado que possa contemplar os assuntos que compõem o interesse desse público. Esse material, portanto, precisa ter ligação com a realidade em que vivem ou trabalham e provocar neles a autonomia, dando-lhes ferramentas para a sua formação profissional e pessoal (FREIRE, 1981).

Essas ferramentas estão asseguradas e recomendadas pelos próprios Parâmetros Curriculares de Língua Estrangeira (Brasil, 1998), que afirmam que o ensino de língua estrangeira precisa conduzir para o caminho da construção da cidadania e para a constituição do aluno como sujeito da aprendizagem, podendo transformar o mundo a sua volta e estimulando o interesse, a curiosidade, o espírito de investigação e o desenvolvimento da capacidade para compreender e comunicar-se.

Se tomarmos o caso específico da língua espanhola, as Orientações Curriculares para o Ensino Médio - Conhecimento de Espanhol (Linguagens, códigos e suas tecnologias) - nos chamam a atenção sobre "[...] o papel educativo que pode ou deve ter o ensino de línguas, em especial do Espanhol, na formação do estudante, naquilo que este lhe proporciona em termos de inclusão social e étnica, na constituição de sua cidadania" (Brasil, 2006, p. 129). Sendo assim, o ensino/aprendizagem de língua estrangeira viabiliza processos de 
emancipação, uma vez que promove a prática social através da possibilidade de compreender/expressar, oralmente e por escrito: opiniões, sentimentos, valores e informações. Rojo e Moita Lopes (2004, p.43), nos dizem que:

A aula de língua estrangeira deve ser um espaço de acesso a diversos discursos que circulam globalmente, para construir outros discursos alternativos que possam colaborar na luta política contra a hegemonia, pela diversidade, pela multiplicidade da experiência humana, $e$ ao mesmo tempo, ela colaborar na inclusão, de muitos brasileiros que estão excluídos de conhecimentos indispensáveis ao convívio contemporâneo. (ROJO; MOITA LOPES, 2004, p. 43)

Em outras palavras, o ensino/aprendizagem de LE oferece oportunidades de perceber e experienciar a comunicação como troca de ideais e de valores culturais, além de estimular o aluno na continuidade de seus estudos e de possibilitar a comparação de suas experiências de vida com as de outros povos. Partindo desses pressupostos, podemos afirmar que o ensino de línguas estaria intimamente ligado às questões da cidadania.

Destarte, dando ferramentas para esse público é possível que ele exercer a cidadania e constituir-se como um cidadão social e político. Em outras palavras, é possível inferir então que o ensino/aprendizagem de uma LE pode auxiliar na promoção de processos de emancipação.

$\mathrm{O}$ processo de entender a cidadania como um processo de e para a emancipação é defendida por Blanco quando nos leva a refletir sobre a relação entre educação e cidadania. Ele nos afirma que:

Além dos atuais desafios de garantir direitos e uma inclusão pelo viés da cidadania a uma população historicamente marginalizada, compreender as expectativas de mobilidade $e$ integração social dos atores envolvidos, bem como seu imaginário sobre os limites e possibilidades das políticas de inclusão a eles destinadas, também torna-se urgente e relevante para a efetividade de programas que tem como finalidade a diminuição das desigualdades sociais 
O ensino da LE como ferramenta para a emancipação...

oferecendo oportunidades de acesso à educação, trabalho e cidadania para populações em situação de pobreza. (2010, p.11)

Nesse mesmo contexto, Jordão explica que:

Aprender e ensinar uma língua estrangeira, portanto, aparece nessa perspectiva como elemento extremamente importante na formação dos cidadãos. É na língua que as pessoas se inserem nas relações políticas locais e mundiais, $e$ é nela também que são promovidos nossos entendimentos dos outros e de nós mesmos, bem como do que há ou não há de nós em outros e de outros em nós. É na língua, particularmente na língua estrangeira, que nos deparamos mais abertamente com nossa alteridade, que encontramos $e$ confrontamos o diferente, que podemos ampliar significativamente nossa percepção das formações discursivas que nos permeiam, e a partir do confronto promovido entre elas, construir sempre novos procedimentos interpretativos. $(2007$, p.28)

As ideias discorridas por Jordão corroboram o pensamento defendido pelo próprio governo brasileiro, quando, através dos Parâmetros Curriculares da EJA (PCEJA), afirma que:

$O$ ensino de Língua Estrangeira tem, portanto, um papel importante na formação interdisciplinar dos alunos jovens $e$ adultos, na medida em que contribui para a construção da cidadania e favorece a participação social, permitindo que ampliem a compreensão do mundo em que vivem, reflitam sobre ele e possam nele intervir. Por outro lado, o desenvolvimento linguístico dos alunos ajuda-os a aperfeiçoar a leitura e a escrita, bem como a compreender as estruturas linguísticas e discursivas - inclusive da língua materna. (BRASIL, PCEJA, 2002, p.67)

Nos parágrafos seguintes, discorremos de maneira mais didática como o ensino/aprendizagem de uma LE pode auxiliar nesse processo emancipatório dos sujeitos da EJA. 


\section{De que maneira as emancipações podem ser desenvolvidas?}

Com o intuito de estabelecer um entendimento mais objetivo sobre a relação entre emancipação e ensino de línguas, consideremos propor, inicialmente, nove mecanismos que julgamos estarem relacionados ao processo de ensino/aprendizagem de línguas paras as pessoas da EJA. Esses mecanismos seriam: 3.1 Conhecimento cultural e intercultural; $3.2 \mathrm{O}$ acesso à leitura; 3.3 Fatores de ordem emocional: autoestima; 3.4 Fatores de ordem socioeconômica: mercado de trabalho; 3.5 Manejo de novas tecnologias; 3.6 Desenvolvimento do letramento; 3.7 Opções de Lazer-entretenimento; 3.8 Multiplicidade de olhares; 3.9 Desenvolvimento de ações para a autonomia.

\subsection{Conhecimento cultural e intercultural}

Se tomarmos como exemplo as aulas de espanhol como LE há uma gama diversa dentro do mundo hispânico para se explorar através da interculturalidade nas aulas no que concerne às possíveis relações e laços existentes entre a formação do povo brasileiro e dos povos hispano-americanos. Nesse sentido, o aluno tem a possibilidade de perceber as inter-relações que perpassam por questões como raça, costumes, manifestações culturais entre tantos outros. A importância que reside no fato do professor de LE propor o contato do aluno brasileiro com objetos e manifestações da matriz africana, por exemplo, na formação da cultura latino-americana, ajuda a criar laços e estabelecer comparações entre as diferentes culturas e povos, facilitando assim a percepção do outro e possibilitando, nesse contexto, entender melhor a si mesmo e à sua própria cultura.

De acordo com Lopes (1996 apud Mota, 2004, p. 40) “A aprendizagem de uma LE, ao contrário do que podem pensar alguns, fornece talvez o material primeiro para o entendimento de si mesmo e de sua própria cultura, já que há o distanciamento crítico através da aproximação com uma cultura".

Mota (2004) defende que a educação multicultural pretende recontextualizar o papel da escola, discutindo a adoção de novos currículos multirreferenciais que venham a incorporar discursos historicamente silenciados e a desprezar aqueles potencialmente silenciadores. $\mathrm{O}$ autor propõe ainda que é nessa proposta multicultural 
que o professor de LE redimensionará o seu papel profissional, distanciando-se de uma postura de alienação e aproximando-se de um comprometimento com a transformação social. Dessa forma, o professor se tornará um educador intelectual, um agente de mudança, engajado na desconstrução de estereótipos e na promoção da tolerância das diferenças. (CELANI, 1997).

$\mathrm{Na}$ visão de Freire, a cultura é um fenômeno profundamente complexo e rico e engloba uma variedade de manifestações, compreendendo, então, que a cultura não é só a manifestação artística e intelectual que se expressa no pensamento. A cultura manifesta-se, sobretudo, nos gestos mais simples da vida cotidiana. Cultura é comer de modo diferente, é dar a mão de modo diferente, é relacionar-se com o outro de outro modo. A nosso ver, a utilização destes três conceitos cultura, diferenças, tolerância - é um modo novo de usar velhos conceitos. Cultura para nós, gostamos de frisar, são todas as manifestações humanas, inclusive o cotidiano. E é no cotidiano que se dá algo essencial: o descobrimento da diferença.

O reconhecimento de uma bagagem cultural trazida e disposta na figura do analfabeto não era, para Paulo Freire, uma simples estratégia pedagógica. Esse entendimento trazia em seu cerne uma maneira de lidar com as diferenças culturais não pelo simples respeito à diferença, mas, e sobretudo, pela ênfase e pelo estímulo à troca entre os diferentes sujeitos e os saberes presentes nas diversas relações pedagógicas. Essas questões podem nos levar também a pensar a respeito do reconhecimento pelo empowerment ${ }^{3}$ desse adulto, principalmente aos que compõem as classes sociais mais subalternizadas e excluídas.

${ }^{3}$ É importante ressaltar que a expressão aqui utilizada não deva entender-se como sinônimo de emancipação. Em sua forma literal, o termo inglês empowerment significa "empoderamento", um neologismo que designa as relações de poder dentro de uma sociedade. O empowerment como fenômeno sociológico está muitas vezes relacionado com membros de grupos que são discriminados pela sua raça, religião ou sexo. Ele se refere a um aumento de força política e social desse grupo ou de um único indivíduo discriminado, através do fortalecimento de suas próprias capacidades. 


\section{$3.2 \mathrm{O}$ acesso à leitura}

A aula de LE possibilita ao aluno da EJA o contato com uma série de diversificados textos e tipologias textuais. Segundo os PCNLE (Parâmetros Curriculares Nacionais de Língua Estrangeira), o desenvolvimento da compreensão leitora é de extrema importância, uma vez que esta é imprescindível para os alunos à hora de fazer provas - como o vestibular, admissão em cursos e concursos - e de compreender escritos acadêmicos, ou seja, é uma habilidade que o aluno poderá utilizar em seu 'contexto social imediato'. (BRASIL,1998).

Quando nos encontramos ministrando aulas para os jovens e adultos, temos que ter consciência de que todos e cada um de nós fazemos parte de um processo de aprendizagem que ajudará os alunos da EJA a desenvolver práticas de leitura e de produção textual mais eficazes. Ao utilizar os Cadernos da EJA, o professor deve estar atento que esses materiais complementam opiniões, muitas vezes questionadas no cotidiano, o que gera um debate saudável, dinâmico e, principalmente real.

Estes questionamentos, muitas vezes gerados pelos assuntos do dia a dia dos próprios alunos, trazem um enriquecimento das atividades propostas nos cadernos. Os exercícios da produção textual propostos pelos cadernos motivam aos estudantes a produzir uma escrita, resumida, objetiva, que expressa, muitas vezes, suas inquietações acerca de temas pouco discutidos em sala por falta de um direcionamento do próprio professor. Pereira (2010, p. 9), destaca que "Ler é questionar um texto, isto é, construir ativamente um significado, em função de suas necessidades e de seus projetos, a partir de diferentes princípios, de natureza distinta, e de estratégias pertinentes para articulá-los".

3.3 Fatores de ordem emocional: autoestima

A autoestima, por sua vez, é também um fator interno preponderante na aprendizagem de línguas. Ela vincula, entre outros aspectos, fatores como inibição, extroversão, empatia, ansiedade, atitudes, egocentrismo, conforme salienta Lago (2000). Todas essas afetividades podem contribuir para o sucesso ou fracasso do aprendiz 
no contexto de aprendizagem, uma vez que o aluno, quando aprende uma língua, acaba por instaurar dentro de si alguns desses domínios afetivos.

Lago (2000) considera o fato de a autoestima ser primordial no processo, uma vez que, quando elevada, se converte em segurança, encorajando e fornecendo ao aluno subsídios para desenvolver tarefas ainda maiores. Ao mesmo tempo, se ocorrer o contrário, o aluno diminuirá seu empenho, transformando o que era aprendizagem em atividade frustrante. A capacidade de aprender uma LE depende ainda de fatores externos, advindos da cultura de aprender que os alunos adquirem e carregam ao longo de toda sua experiência intelectual, cultural e social.

Flynn (1873 apud Finger, 2005, p.32) assegura que "diferenças de maturação entre os adultos e crianças não afetam significativamente a faculdade da linguagem". Assim, essa proposição da autora parece desmitificar a ideia de que o maior empecilho no aprendizado de língua estrangeira seja a idade. Isso porque muitos adultos aprendem uma língua por vontade motivacional. Por sua vez, Stevick (1980) afirma que o êxito no aprendizado de uma língua estrangeira depende menos dos materiais, técnicas e análises linguísticas e mais do que ocorre entre as pessoas e dentro delas.

\subsection{Fatores de ordem socioeconômica: mercado de trabalho}

$\mathrm{O}$ ensino de um idioma estrangeiro, no que se refere às relações de trabalho e aos meios de profissionalização, deve estar diretamente relacionado e adaptado às novas necessidades do mercado e aos novos processos de comunicação que hoje dominam o mundo moderno.

Como já foi dito em algumas partes deste artigo, o ensino, neste caso, deve primar para uma ampla formação do indivíduo, de forma que ele possa apresentar um diferencial no meio profissional em que está inserido. Hoje, é essencial manter-se informado e, sobretudo, saber buscar informações pertinentes que nem sempre se apresentam em português ou traduzidas para o português. De acordo com Witte (2006), o profissional de hoje precisa manter-se informado em um mundo cada vez mais globalizado; um profissional de qualquer área terá a necessidade de ler sobre todas elas, e não somente sobre sua 
atividade de atuação, porque é preciso ter uma visão global do mundo. Também, com o grande número de empresas multinacionais que se instalam no país a cada dia, a importância da fluência em idioma estrangeiro tornou-se essencial.

$\mathrm{O}$ inglês e o espanhol são sem dúvida os idiomas mais requisitados pelas empresas não só estrangeiras, mas também nacionais. Estas últimas procuram abrir sua economia ao mercado internacional e exigem de seus funcionários não apenas o conhecimento básico do idioma, mas o seu domínio.

Assim, para que o ensino de línguas seja eficiente, deve incorporar aos contextos comunicacionais fatores relevantes do processo mercadológico moderno.

Hoje, o que nos é oferecido geralmente são cursos de inglês ou espanhol em 'pacotes', que não priorizam o estudo linguístico em situações específicas do dia a dia de cada profissão. Esses cursos acabam por massificar o ensino e apresentam a língua estrangeira fora de um contexto aplicável. Urge, portanto, a elaboração de estratégias de ensino que possam suprir as necessidades do profissional moderno para que ele adquira com eficiência a habilidade de saber se comunicar em todos os contextos a que for exposto.

Assim também a PCEJA de língua estrangeira defende que:

A aprendizagem de línguas estrangeiras, compreendida como um direito básico de todas as pessoas e uma resposta a necessidades individuais e sociais do homem contemporâneo - não só como forma de inserção no mundo do trabalho, mas também, principalmente, como forma de promover a participação social -, tem papel fundamental na formação dos jovens e adultos. A língua estrangeira permite o acesso a uma ampla rede de comunicação e à grande quantidade de informações presentes na sociedade atual. (BRASIL, PCEJA, 2002, p. 67)

\subsection{Manejo de novas tecnologias}

As novas tecnologias e mídias fazem parte do cotidiano das pessoas da EJA e não se pode ter o preconceito de pensar que, por serem indivíduos adultos e muitas vezes trabalhadores, estes não teriam necessidade de ter acesso às novidades tecnológicas e de mídia 
tão presentes no mundo globalizado que vivemos. Já no início do manual dos PCN-LCT (Parâmetros Curriculares Nacionais de Linguagens, Códigos e Tecnologias), na parte destinada ao ensino de língua estrangeira, estão as seguintes palavras "As línguas estrangeiras assumem a condição de ser parte indissolúvel do conjunto de conhecimentos essenciais que permitem ao estudante aproximar-se de várias culturas e, consequentemente, propiciam sua integração num mundo globalizado". (Brasil, 2000b, p. 25). Nessa perspectiva, os PCN-LCT atestam que o ensino da LE "tem como princípio geral levar o aluno a comunicar-se de maneira adequada em diferentes situações da vida cotidiana" (Ibidem, p. 26).

Além de ressaltar o caráter educacional e cultural do ensino e aprendizagem de língua estrangeira, os PCN-LE também reconhecem a importância econômica e social do domínio de língua estrangeira e de sua função diante dessa sociedade globalizada, em que se necessita dominar as habilidades para lidar com as novas tecnologias. (BRASIL, 1998)

Os PCN-LE explicitam, de forma clara e contundente, que o aluno pós-moderno precisa dominar a língua estrangeira para que esteja inserido nesta sociedade da comunicação, podendo ter, por intermédio da língua estrangeira, acesso a bons estudos, boas oportunidades, bons empregos. Ou seja, "O desenvolvimento de habilidades comunicativas, em mais de uma língua, é fundamental para o acesso à sociedade da informação. Para que as pessoas tenham acesso mais igualitário ao mundo acadêmico, ao mundo dos negócios e ao mundo da tecnologia etc." (Ibidem, p. 38).

\subsection{Desenvolvimento do letramento}

As OCEM afirmam que o processo de ensino e aprendizagem de uma LE está atrelado às questões relativas ao desenvolvimento do letramento além de promover processos de inclusão. Para as OCEM, as aulas de LE possibilitam:

[...] ressaltar a importância dessas; reafirmar a relevância da noção de cidadania e discutir a prática dessa noção [...] discutir o problema da exclusão no ensino em face de valores "globalizantes" e o sentimento de inclusão 
frequentemente aliado ao conhecimento de Línguas Estrangeiras [...] introduzir as teorias sobre a linguagem e as novas tecnologias (letramentos, multiletramentos, multimodalidade, hipertexto) e dar sugestões sobre a prática do ensino de Línguas Estrangeiras por meio dessas. (BRASIL, 2006, p.87)

É perceptível que seus autores afirmam que a aprendizagem de leitura em língua estrangeira auxilia no processo do desenvolvimento global do letramento ${ }^{4}$ do aluno. A leitura, nesse sentido, tem função essencial na escola e aprender a ler em língua estrangeira pode ajudar no manejo do aluno como leitor em sua língua materna (Brasil, 1998). Os PCN-LE afirmam que "[...] a aprendizagem de leitura em língua estrangeira pode ajudar o desenvolvimento integral do letramento do aluno" (BRASIL, 1998, p. 20).

\subsection{Opções de lazer-entretenimento}

Em relação a essa questão, a PCEJA de língua estrangeira nos afirma que:

Especificamente no contexto da EJA, o ensino de Língua Estrangeira amplia as possibilidades de ascensão profissional, as opções de lazer, o interesse pela leitura e pela escrita e a percepção da escola como um contexto para a constituição da identidade do aluno. (BRASIL, PCEJA, 2002, p.68)

Além do mais, o ensino de uma língua estrangeira:

Proporciona uma perspectiva mais abrangente de situações de lazer, permitindo que os jovens e adultos possam tirar maior proveito da leitura de livros, jornais e revistas, compreender melhor filmes, telejornais, documentários, entrevistas, novelas etc. Além disso, aumenta a amplitude do

\footnotetext{
${ }^{4} \mathrm{O}$ resultado da ação de ensinar a ler e escrever. É o estado ou a condição que adquire um grupo social ou um indivíduo como consequência de ter-se apropriado da escrita (SOARES, 2002, p. 17).
} 
O ensino da LE como ferramenta para a emancipação...

universo estético, pela leitura de diferentes obras - não necessariamente na língua estrangeira, mas também em traduções. (Ibidem, p.68)

Muitos tendem a encarar o público da EJA com um olhar preconceituoso, como se os indivíduos que compõem essa modalidade de ensino não precisassem ou não tivessem interesse em acessar as mais variadas formas de cultura e suas correlações com o ócio e o prazer. O contato com a língua estrangeira pode proporcionar, nesse contexto, a aproximação com variadas formas de manifestações culturais dos países estudados, podendo assim ser utilizada como um instrumento que promove o lazer e entretenimento das pessoas da EJA.

3.8 Multiplicidade de olhares

O ensino de línguas para a EJA precisa proporcionar a multiplicidade de olhares, não um mundo hispânico composto somente da realidade da Espanha ou de um país em detrimento do outro. Nesse contexto, o mundo hispânico, antes composto só de Shakira, Alejandro Sánz, Maná, flamenco e tourada, ganha dimensões bem maiores, complexas e profundas, possibilitando um leque maior, com novas caras, novas músicas, novas cores, novas letras, novos sabores e saberes. Para Mota:

Desenvolver a multiplicidade de olhares na percepção das culturas estrangeiras; redescobrir os valores culturais das identidades de origem dos aprendizes; viabilizar um intercâmbio constante entre as múltiplas identidades que permeiam os universos pessoais e profissionais de cada indivíduo; afirmar o posicionamento político de minorias marginalizadas. (2004, p. 48-49)

Nesse processo, um dos grandes desafios é desvelar, desfazer, desconstruir os estereótipos raciais e a antiga visão herdada da colonização do 'racismo cordial'. Isso perpassa pelo reconhecimento das diferenças como um elemento fundante e primordial de qualquer sociedade democrática. Para Cardoso, os estereótipos são "imagensrótulos que as pessoas de um grupo/cultura atribuem às pessoas de outro grupo/cultura baseadas em argumentos não comprovados. [...] Os 
estereótipos podem ser positivos ou negativos e são aplicados a todos os membros do grupo sem consideração por diferenças individuais" (Cardoso, 1996, p. 18). Os PCN de LE (Brasil, 1998), nesse sentido, defendem que essas ações - bases essenciais para se pensar em uma educação intercultural - devem antes de tudo ter seu apoio na escola. A questão do entendimento e da importância da pluralidade cultural e os mecanismos para a interculturalidade têm no papel da escola um objeto fundamental.

A pesar de haver certa tendência de falar sobre a importância e a necessidade de aprender o inglês, os PCN-LE afirmam que o tema da diversidade cultural deve ser aplicado em qualquer aula de língua estrangeira no Brasil. Desse modo, defende-se que o ensino da língua estrangeira deve ser feito em um contexto intercultural uma vez que possibilita enxergar não somente as similitudes, mas também as diferenças. Essas percepções tem o caráter de desenvolver um alunado mais crítico, o que deve ser construído num princípio que o que seja tratado tenha relação como o dia a dia do alunado e sua realidade. (BRASIL, 1998)

3.9 Desenvolvimento de ações para a autonomia

De maneira geral, acreditamos que todas as oito categorias apontadas incidam para e na nona categoria. Entendemos, nesse processo, que todos os mecanismos abordados permitem processos emancipatórios para as pessoas da EJA. Em relação à questão específica da autonomia, os PCN-LE reconhecem várias vezes a importância do ensino e aprendizagem da língua estrangeira, afirmando que esta contribui para o processo educacional como um todo, indo muito além da aquisição de um conjunto de habilidades linguísticas. (BRASIL, 1998).

\section{Nem tudo são flores: algumas reflexões finais}

As questões expostas nesse artigo nos levam a refletir sobre as potencialidades do ensino e aprendizagem das LE para as pessoas da EJA. Contudo, cabem algumas ações para além das reflexões. É importante perceber e colocar em prática uma formação de professores 
de LE que contemple o contato junto às pessoas da EJA, fazendo-os compreender as especificidades, necessidades e multiplicidades dos sujeitos que compõem essa modalidade. Assim, conhecendo esses sujeitos, é possível se pensar em aulas de LE com metodologias, estratégias e materiais didáticos que possam contribuir de maneira significativa para a formação do indivíduo em um processo emancipatório.

Entretanto, não adiantará promover uma formação qualificada dos professores de LE para o trabalho junto à EJA se esse público não tiver sequer no mínimo o acesso à oferta da língua estrangeira em suas escolas. Não adianta falar de procedimentos teóricos ou metodológicos para melhorar a prática educativa do ensino de línguas para a EJA se sequer a LE não foi ofertada para esse público.

Infelizmente, muitas escolas do Brasil ainda não oferecem de maneira satisfatória e regular o ensino de línguas na EJA. Há escolas que somente oferecerem o inglês, e há outras em que o inglês é ofertado somente para um dos segmentos da EJA. Em relação ao espanhol, há escolas que já não o ofereciam, mesmo este sendo apoiado pela Lei 11.161, de agosto de 2005, que o tornou obrigatório no ensino médio. A situação do espanhol tornou-se ainda mais dramática quando em 2016 a lei foi revogada pelo governo em vigor. $\mathrm{E}$, se falarmos de idiomas como o francês e o italiano, quase não existem mais nas grades curriculares das escolas brasileiras.

Outro ponto importante que se soma à problemática de fazer o ensino/aprendizagem eficaz nas aulas de EJA é a dificuldade em encontrar materiais didáticos. O material é escasso e, quando existe algum tipo de guia, compêndio, áudio ou afim que de fato seja referencial para o uso em uma aula da EJA, é de difícil acesso (quase sempre está indisponível para venda ou não existe mais no estoque).

É frustrante perceber que as prateleiras de materiais especializados em ensino e aprendizagem de línguas atendem a demandas como: ensino de língua para o turismo, para hotelaria, para administração, para crianças, para secretariado executivo, para negócios, para viagens, entre tantos outros, mas não se encontra nada ou quase nada especializado e pensado para o público da EJA. Seria por um acaso mais um preconceito sofrido pelas pessoas da EJA?

Diante de todo este contexto e da importância no âmbito social e econômico do ensino e aprendizagem da língua estrangeira para o 
público da EJA, urge uma discussão sobre a formação do professor de língua estrangeira. Se dermos uma olhada, ainda que superficial sobre o currículo dos cursos de língua estrangeira, mais especificamente seus programas de disciplina, poderemos perceber que a educação de jovens e adultos pouco aparece, é discutida ou faz parte desse cenário.

Se tomarmos como exemplo a disciplina de estágio, que normalmente é oferecida nas etapas finais dos cursos de licenciatura em línguas - que em algumas universidades é dividida em estágio I, II, III e IV -, e dermos uma olhada específica sobre seu programa de disciplina, poderemos perceber que, em muitas universidades, os alunos de estágio supervisionado nunca tiveram contato com o público da EJA. Assim, situações como essas acabam impossibilitando que os futuros professores de LE conheçam as especificidades desse público. $\mathrm{O}$ não conhecimento dessas especificidades pode prejudicar o ensino/aprendizagem da LE no âmbito teórico, metodológico e didático, dificultando, de fato, que as aulas se tornem significativas para as pessoas da EJA.

Podemos perceber que, em muitas universidades brasileiras, o graduando em língua estrangeira acaba concluindo seu curso sem nenhum ou com pouquíssimo contato e entendimento do que é a EJA. Com isso, não consegue acessar ferramentas específicas no trabalho em sala de aula de língua estrangeira para a EJA.

Esse mecanismo é ainda mais complexo e profundo se tomarmos como premissa que muitos dos professores, dentro da universidade, que lecionam a disciplina de estágio, por exemplo, em sua formação, não tiveram acesso e entendimento sobre a EJA. Dessa maneira, essa falta de conhecimento específico é refletida em sua própria disciplina. Essas reflexões nos fazem lembrar as ideias defendidas por Barcelos (2006) quando aponta que a formação do professor para a EJA passa primeiramente pelo entendimento de quem são as pessoas que fazem parte da EJA.

Em outras palavras, a solução para a problemática levantada talvez esteja, em um primeiro estágio, na formação e qualificação continuada dos professores universitários dos cursos de licenciatura em língua estrangeira quanto à preparação e entendimento da EJA e, em um segundo estágio, partindo do pressuposto que esses professores estarão qualificados, na preparação dos alunos/licenciandos para a atuação junto ao público da EJA - seja através, a princípio, da 
disciplina de estágio ou gradativamente sendo visto e debatido em outras tantas disciplinas dos cursos de licenciatura em língua estrangeira.

Entendemos, dessa forma, que o ensino de LE só poderá gerar processos emancipatórios para as pessoas da EJA se essas aulas forem significativas para os sujeitos que compõem essa modalidade. E isso perpassa por uma formação docente comprometida e voltada para o entendimento das especificidades e necessidades das pessoas da educação de jovens e adultos. Ou seja, esse processo centra-se na importância do papel do professor para a mudança da situação atual.

O papel do professor, nesse cenário, assume uma forma ainda mais importante e essencial. Se em muitos casos, como nas ditas classes ou modalidades consideradas como 'regulares' já se encontra a maior dificuldade em ofertar e oportunizar o acesso ao ensino das línguas estrangeiras, quando tratamos sobre as pessoas da EJA essa problemática ganha uma dimensão ainda maior. É preciso, por parte do professorado de LE, um olhar sensível quanto a necessidade e relevância social do ensino e aprendizagem de língua estrangeira para os indivíduos da EJA.

\section{Referências}

BAGNO, M.; RANGEL, E. O. Tarefas da educação linguística no Brasil. Revista Brasileira de Linguística Aplicada, v. 5, n. 1, p. 63-81, 2005.

BARTHES, R. Aula. São Paulo: Ed. Cultrix, 1997.

BLANCO, D. M. O Projovem urbano e perspectivas de análises. Revista Brasileira de História \& Ciências Sociais, v. 2, n. 3, p. 10-21, 2010.

BRANDÃO, C. R. A educação popular na escola cidadã. Petrópolis, RJ: Vozes, 2002. 
BRASIL. Secretaria de Educação Básica. Orientações curriculares para o ensino médio: conhecimentos de línguas estrangeiras. Brasília: Ministério da Educação, Secretaria de Educação Básica, 2006.

Secretaria de Educação Fundamental. Parâmetros curriculares nacionais: língua estrangeira: 5a.- 8a. séries. MEC. Brasília, 1998.

- Parecer CNE/CEB 11/2000: diretrizes curriculares nacionais para a educação de jovens e adultos. Brasília: Câmara de Educação Básica, 2000a. Disponível em: <http://portal.mec.gov.br/cne/arquivos/pdf/PCB11_2000.pdf>. Acesso em: 20 set. 2016.

- Secretaria de Educação Fundamental. Proposta curricular para a educação de jovens e adultos: segundo segmento do Ensino Fundamental: $5^{\mathrm{a}}$ a $8^{\mathrm{a}}$ séries. Brasília: MEC/SEF.2002. Disponível em: http://portal.mec.gov.br/secad/arquivos/pdf/eja/propostacurricular/segu ndosegmento/vol2_linguaestrangeira.pdf. Acesso em: 20 mar. 2016.

- Ministério da Educação e do Desporto. Secretaria de Educação Fundamental. Parâmetros curriculares nacionais: ensino médio: parte II: linguagens, códigos e suas tecnologias. MEC. Brasília, 2000b.

BRITO, L. P. L. A sombra do caos: ensino de língua X tradição gramatical. Campinas: Mercado de Letras; ALB, 1997.

. Escola, ensino de língua, letramento e conhecimento.

Calidoscópio, v. 5, n. 1, p. 24-30, 2007.

CARDOSO, C. Educação multicultural: percursos para práticas reflexivas. Lisboa: Texto Editora, 1996.

CARVALHO, A. M. P. D. Experiências emancipatórias em tempos de crise e transição: potencialidades da utopia democrática. In: CONGRESSO PORTUGUÊS DE SOCIOLOGIA MUNDOS SOCIAIS: SABERES E PRÁTICAS, 2008, Lisboa. Anais... Lisboa, 2008. 
O ensino da LE como ferramenta para a emancipação...

CELANI, M. A. A. Ensino de línguas estrangeiras: olhando para o futuro. In: (Org.) O ensino de segunda língua: redescobrindo as origens. São Paulo: EDUC, p. 147-161, 1997.

FEITOZA, R. Movimentos de educação de pessoas jovens e adultas na perspectiva da educação popular no Amazonas: matrizes históricas, marcos conceituais e impactos políticos. Tese (Doutorado em Educação) - Centro de Educação da Universidade Federal da Paraíba, João Pessoa, 2008.

FILHO, L. O problema da educação de adultos. Revista Brasileira de Estudos Pedagógicos, v.81, n. 197, p. 116-127, 2000.

FINGER, I. Sobre a relação entre GU e aquisição de segunda língua. Revista Signo, v. 24, n. 36, p. 61-76, 2005.

FOUCAULT, M. Estratégia, poder-saber. 2 ed. Manoel B. da Motta (Org.) e Tradução Vera L. A. Ribeiro. (Ditos e Escritos IV). Rio de Janeiro: Forense Universitária, 2006.

. A ordem do discurso. 3. ed. Trad. L. F. de A. Sampaio. São Paulo: Edições Loyola, 1996. . Microfísica do poder. Rio de Janeiro: Graal, 1979.

FREIRE, P. Pedagogia da esperança: um reencontro com a pedagogia do oprimido. 3. ed. Rio de Janeiro: Paz e terra, 1992.

. Educação como prática da liberdade. 12. ed. Rio de Janeiro: Paz e Terra,1981.

1997.

. Educação e mudança. Rio de Janeiro: Paz e Terra, . Política e educação. São Paulo. Cortez, 1993. 
GALEANO, E. O livro dos abraços. Porto Alegre: L\&PM, 2002.

GOMES, N. L. Educação de jovens e adultos e questão racial: algumas reflexões iniciais. In: SOARES, L.; GIOVANETTI, M. A.; GOMES, N. L. (Org.). Diálogos na educação de jovens e adultos. Belo Horizonte: Autêntica, 2005. p. 87-104.

JORDÃO, C. M. A. As lentes do discurso: letramento e criticidade no mundo digital. Trabalhos em Linguística Aplicada, Campinas, SP, v. 46, n. 1, p. 19-29, Jan./Jun, 2007.

KLEIMAN, A. Os significados do letramento: uma nova perspectiva sobre a prática social da escrita. Campinas: Mercado de Letras, 1995.

LAGO, S. N. A. Explorando a auto-estima na aquisição de segunda língua. In: MELLO, H.A.B; DALACORTE, M. C. F. (Org.). A sala de aula de língua estrangeira. Goiânia: Editora UFG, , 2000. p.83 -100.

LOPES, E. S. Por que falar das pedras? In: OLIVEIRA, I. B. (Org.). Práticas cotidianas e emancipação social: do invisível ao possível. Petrópolis, RJ: DP et Alii, 2010. p. 120-138.

MOREIRA, A. F. B.; CANDAU, V. M. (Orgs.). Multiculturalismo: diferenças culturais e práticas pedagógicas. Petrópolis, RJ: Vozes, 2008.

MOTA, K. Recortes interculturais na sala de aula de línguas estrangeiras. Bahia: Editora da UFBA, 2004.

OLIVEIRA, I. A. de. Educação de jovens, adultos e idosos. Salto para o Futuro. Volume temático: Educação ao longo da vida, ano 19, n. 11, p. 14-19, 2009.

Educação de jovens e adultos: um campo de direitos e de responsabilidade pública. In: SOARES, Leôncio; GIOVANETTI, Maria Amélia; GOMES, Nilma Lino (Orgs.). Diálogos na educação de jovens e adultos. Belo Horizonte: Autêntica, 2005. p. 19-50. 
O ensino da LE como ferramenta para a emancipação...

PEREIRA, G. Preferencias adaptativas: un desafío para el diseño de las políticas sociales. Revista de Filosofía Moral y Política, n. 36, p. 225-239, 2007.

PEREIRA, M. T. G. Ler, refletir, expressar: uma proposta de ensino da língua portuguesa para a educação de jovens e adultos (EJA). SEEJA, 2010.

ROJO, R. H. R.; MOITA LOPES, L. P. Linguagens, códigos e suas tecnologias. In: BRASIL/SEB/MEC. Orientações curriculares do ensino médio. Brasília: SEB/MEC, 2004. p. 14-59.

SANTOS, B. S. (Org.). Democratizar a democracia. Rio de Janeiro: Civilização Brasileira, 2002.

- Pela mão de Alice: o social e o político na pósmodernidade. 12. ed. São Paulo: Cortez, 2008.

SILVA, M. M. O ensino da língua inglesa aos alunos da EJA. Vida de Ensino, v. 2, n.2, p. 40-47, 2010.

SOARES, M. Letramento: um tema em três gêneros. 2. ed. Belo Horizonte: Editora Autêntica, 2002.

. Português: uma proposta para o letramento. Livro do Professor. São Paulo: Moderna, 1999.

. Letramento e alfabetização: as muitas facetas. Revista de Educação, n. 25, p. 44-56, 2004.

STEVICK, R. Teaching languages: a way and ways. Oxford: OUP, 1980.

STREET, B. Literacy in theory and practice. Cambridge: Cambridge University Press, 1984.

WITTE, R. E. Business English: a practical approach. 2. ed. São Paulo: Saraiva, 2006. 
José Veiga Vinal Junior

Recebido em: 10/04/2017

Aceito em: 07/07/2017

Title: The teaching of a foreign language as a tool for the emancipation of the people from the Youth and Adult Education in Brazil: potentials and reflections 